\title{
Methane, Monsoons, and Modulation of Millennial-scale Climate
}

\author{
Kaustubh Thirumalai ${ }^{1}$, Steven C. Clemens ${ }^{2}$, Judson W. Partin ${ }^{3}$ \\ ${ }^{1}$ Department of Geosciences, University of Arizona, Tucson, AZ, USA \\ ${ }^{2}$ Department of Earth, Environmental, and Planetary Sciences, Brown University, Providence, RI, USA \\ ${ }^{3}$ Institute for Geophysics, Jackson School of Geosciences, University of Texas at Austin, Austin, TX, USA
}

\section{Key Points:}

- We assess the extent to which orbital forcing modulates millennial-scale climate variability.

- Millennial variations in atmospheric methane are directly modulated by precession whereas those in Chinese speleothem $\delta^{18} \mathrm{O}$ are not.

- We propose that this decoupling has important consequences for understanding drivers and feedbacks in the climate system. 


\begin{abstract}
Earth's orbital geometry exerts a profound influence on climate by regulating changes in incoming solar radiation. Superimposed on orbitally-paced climate change, Pleistocene records reveal substantial millennial-scale variability characterized by trends, tipping points, and rapid swings. However, the extent to which orbital forcing modulates the amplitude and timing of these millennial variations is unclear. Here we isolate the magnitude of millennial-scale variability (MMV) in two well-dated records, both linked to precession cycles (19,000-23,000-year periodicity): atmospheric methane and Chinese speleothem $\delta^{18} \mathrm{O}$, where the latter is commonly interpreted as a proxy for Asian monsoon intensity. At the millennial timescale (1,000-10,000 years), we find a fundamental decoupling wherein precession directly modulates the MMV of methane but not that of speleothem- $\delta^{18} \mathrm{O}$. We hypothesize that mid-to-high latitude insolation modulates the MMV of atmospheric methane, but feedbacks internal to the Earth-climate system modulate the strength of millennialscale monsoonal circulation.
\end{abstract}

\title{
1 Introduction
}

Well-known variations in Earth's orbital parameters have pronounced effects on its insolation (i.e. incoming solar radiation) and climate system. Also known as Milankovitch cycles, imprints of oscillatory changes in orbital precession, obliquity, and/or eccentricity of the Earth's orbit are found in virtually all sufficiently-resolved paleoclimatic records during and beyond the Cenozoic Era. Despite disagreement regarding causal mechanisms [Abe-Ouchi et al., 2013], it is well-established that orbital forcing paced the glacial-interglacial cycles of the late Pleistocene [Imbrie et al., 1992], with a periodicity approximating 100,000 years (hereafter 100-kyr). Regional records of temperature and hydroclimate change also indicate shorter-term variability [Caley et al., 2011] tied to precession (19-kyr and 23-kyr periodicities) and obliquity (41-kyr periodicity). On even shorter timescales, arguably more pertinent to human and societal relevance [Castañeda et al., 2009], high-resolution records reveal abrupt and substantial millennial-scale climate variability (1 to 10-kyr periodicity) superimposed on the more gradual, orbitally-induced changes [Brook and Buizert, 2018]. However, the relationship between millennial-scale climate variability and orbital variations of insolation remains elusive.

Previously, orbitally-paced changes in insolation have been hypothesized to modulate millennial-scale activity in both atmospheric methane [Brook et al., 1996] and the Asian monsoons [Cheng et al., 2016]. Studies have also postulated a strong coupling between monsoon intensity and methane at both precessional and millennial timescales, wherein increased monsoon rainfall is associated with increased methane production via wetland expansion in low-latitude regions [Guo et al., 2011; Ruddiman and Raymo, 2003]. Clarifying their relationship under changing background conditions is important for constraining extreme future scenarios as uncertainties in monsoon hydrology and resultant wetland changes feedback onto the future trajectory of methane [O'Connor et al., 2010; Kirschke et al., 2013; Brook and Buizert, 2018]. However, the proposed mechanisms of how orbital forcing modulates millennial-scale variability are inconsistent: whereas Brook et al. [1996] posit increased millennial-scale methane activity with increased insolation, Cheng et al. [2016] find an anti-phased modulation relationship where high insolation values correspond to weakened monsoon intervals.

Does orbital forcing modulate the magnitude of millennial-scale variability? We define the term 'modulate' following signal-processing literature [Roder, 1931; Rial, 2000] wherein a higher-frequency carrier signal (millennial oscillations of the climate system) is modulated by a lower-frequency input signal (orbital variations) to yield a resultant modulated signal (observed paleoclimate record). Thus, modulation implies a significant control of a longer-timescale signal on shorter-event amplitude or frequency. Here, we isolate the magnitude of millennial-scale variability (MMV) of atmospheric methane and that of 
monsoon intensity over the past $640 \mathrm{kyrs}$ and quantitatively assess the extent to which primary orbital frequencies modulate the millennial band of climate variance. We stress that co-variability and coupling over millennial timescales between atmospheric methane and Chinese speleothem $\delta^{18} \mathrm{O}$ (e.g. both records contain responses to Heinrich events [Marcott et al., 2014; Rhodes et al., 2015]) does not preclude that the amplitude of these two parameters are differently modulated by external factors [Extier et al., 2018]. We show that there is a clear imprint of precession cycles in the MMV of methane whereas we cannot find any signature of insolation directly modulating the MMV of speleothem $\delta^{18} \mathrm{O}$. Finally, we also find a long-term trend in the MMV of speleothem $\delta^{18} \mathrm{O}$ coinciding approximately with the Mid-Brunhes Event ( $430 \mathrm{ka}$ ) whereas no secular trend exists in the MMV of methane.

\section{Methods}

We focus on quantifying the magnitude of millennial-scale variability (MMV) in the EPICA Dome Concordia (EDC) $\mathrm{CH}_{4}$ record [Loulergue et al., 2008] (Fig. 1a) and the Chinese speleothem composite $\delta^{18} \mathrm{O}$ record [Cheng et al., 2016] (Fig. 2a). At first, we assume that the composite purely reflects variations in East Asian monsoon rainfall intensity - the published interpretation [Cheng et al., 2016] - although there is ongoing debate regarding the details of this interpretation [Chiang et al., 2015; Clemens et al., 2018; Beck et al., 2018] which we address in our discussion below. Both records are extremely well-dated and represent state-of-the-art climate reconstructions in terms of their resolution over the past $640 \mathrm{kyrs}$, spanning multiple realizations of Milankovitch cycles. We evaluate the MMV in these records by first filtering them to isolate their millennial components (Figs. $1 \mathrm{~b}$ and $2 \mathrm{~b}$ ). Next, we separate their positive and negative amplitude envelopes (Fig. 1c and 2c) to independently assess the modulation of high-value (e.g., Dansgaard-Oeschger interstadials) versus low-value (e.g., Dansgaard-Oeschger stadials, Heinrich Events) millennial-scale variability. We then calculate a continuous record of the MMV (Figs. 1d and 2d), which reflects a combined metric of both positive- and negativeamplitude variability, derived from the variance in the filtered records (Figs. $1 b$ and $2 b$ ). Finally, we utilize spectral analysis to determine periodicities where variance is concentrated (Figs. 1e-h and 2e-h) and to identify the power of primary orbital frequencies in the MMV of atmospheric methane $\left(\mathrm{MMV}_{\text {methane }}\right)$ and the purported record of East Asian monsoon intensity $\left(\mathrm{MMV}_{\mathrm{China}}\right)$. Although the methane and Chinese $\delta^{18} \mathrm{O}$ records are variable in their timestep resolution as well as in their age-model uncertainties, we show that these effects have little impact on our results (Fig. S1 and Fig. S2). Furthermore, our analysis is insensitive to the various ice-core age models (Fig. S1) and for this work, we use the updated AICC timescale [Bazin et al., 2013].

The MMV in each record was calculated using the following steps. The original time series was filtered using a Butterworth filter at a cutoff threshold of 10 kyrs. Prior to filtering, we interpolated the original time series to a common step of 100 years (changing this value to 50 years or 1000 years did not impact our interpretations; see Fig. S1). The MMV was calculated using a centered rolling standard deviation applied to the high-pass filtered time series with a window of 2 kyrs and a 100-year step (i.e., essentially a continuous window). The outcomes of our study remain unchanged if we reduced our cutoff threshold to 6 kyrs or increased it to 12 kyrs; we justify our choice of 10 so as to include the millennial band frequencies and exclude leakage from hemi-precession frequencies [Hagelberg et al., 1994].

We also calculated the MMV in the following records: ice-volume over the past 640 kyrs (Fig. S3) from a recently compiled probabilistic stack [Spratt and Lisiecki, 2016], the EDC $\delta \mathrm{D}$ record from Antarctica [Jouzel et al., 2007] (Fig. 4c; Fig. S4), the molybdenum XRF composite record from Cariaco Basin, Venezuela [Gibson and Peterson, 2014] (Fig. S5), and the composite Borneo speleothem $\delta^{18} \mathrm{O}$ record [Carolin et al., 2016] from Malaysia (Fig. S6). We normalized orbital eccentricity, tilt, and precession (ETP) param- 
eters over the past 640 kyrs for use in the wavelet coherence calculations (Figs. 3b, 3d) to extract maximal phase and amplitude correlations with orbital forcing. Finally, all analyses evaluating the spectral characteristics of the time series in this study were performed using the Lomb-Scargle periodogram, a method chosen so as to not generate spurious spectral characteristics [VanderPlas, 2017]. Wavelet coherence between time series was performed in a Monte Carlo framework $(\mathrm{n}=1000)$ using published MATLAB codes [Grinsted et al., 2004] wherein each time series was linearly detrended.

\section{Results}

Spectral analysis reveals the dominant influence of orbital forcing in atmospheric methane variability over the past 640 kyrs. In the original ("raw") methane record, the variance is mainly concentrated in the obliquity and eccentricity bands [Chappellaz et al., 1990; Loulergue et al., 2008], to nearly the same magnitude (Fig. 1e). Peaks in the precessional bands are also present, although their magnitudes are comparatively small. Power in the millennial band becomes prominent in the filtered record, which, by construction, does not contain variance in periodicities beyond 10 kyrs (Fig. 1f; note change of scale in axis). Spectra of both high-value and low-value excursions contain separate and distinct peaks in the millennial bands (Fig. 1g), potentially pointing to separate and distinct controls on uptake and release of $\mathrm{CH}_{4}$ during individual events [Siddall et al., 2010]. However, over modulating timescales $(>10-\mathrm{kyr})$, we find that the spectral peaks for both high-value and low-value $\mathrm{CH}_{4}$ are identical. These peaks are also very similar to those observed in the $M M V_{\text {methane }}$ record (Fig. 1h). Most notably, we find strong spectral power in both precessional bands as well as power in the obliquity band for the high-value and low-value records as well as in the MMV of methane (Figs. 1g and h).

On closer inspection, we find that precession minima (i.e., Northern Hemisphere

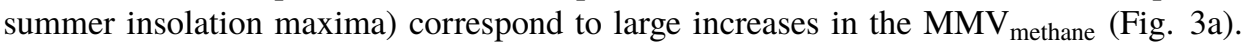
Many of these increases are associated with the release and subsequent drawdown of atmopsheric methane coinciding with precession minima, nearing the culmination of deglaciation (Fig. 3a \& Fig. S3; e.g., over the Bølling-Allerød and Younger Dryas sequence). Conversely, precessional maxima (i.e., Northern Hemisphere summer insolation minima) correspond to reduced $\mathrm{MMV}_{\text {methane }}$ (Fig. 3a). This relationship is insensitive to glacial or interglacial background state (Fig. S3). The amplitude of these swings in MMV often follow the amplitude of precession changes, e.g., a lull in $\mathrm{MMV}_{\text {methane }}$ is observed at $\sim 400$ $\mathrm{ka}$, when variability in precession is subdued. Wavelets analysis reveals strong coherence and near-zero phase with the $19 \mathrm{kyr}$ and $23 \mathrm{kyr}$ bands over the last two glacial cycles, with varying but persistent power over the past 640 kyrs (Fig. 3b). Comparatively weak coherence and out-of-phase relationships are found at the $41 \mathrm{kyr}$ and $101 \mathrm{kyr}$ bands (Fig. $3 \mathrm{~b}$ ), despite the peaks in the periodograms (Fig. $1 \mathrm{~g}$ and $1 \mathrm{~h}$ ), suggesting that $\mathrm{MMV}_{\text {methane }}$ is not directly modulated by either obliquity or eccentricity. Thus, we conclude that precession directly modulates millennial-scale variability in atmospheric methane, supporting the assertion of higher insolation facilitating increased variability [Brook et al., 1996].

In stark contrast, we find no trace of precessional forcing in the modulation of millennialscale speleothem $\delta^{18} \mathrm{O}$ variability (Fig. 2). Variance in the original ("raw") $\delta^{18} \mathrm{O}$ record is dominated by precession (Figs. 2a and 2e), yet, power is absent in the precessional bands of both the high-value and low-value records (Figs. $2 \mathrm{c}$ and $2 \mathrm{~g}$ ), as well as in the MMV record (Figs. 2d and 2h). Instead, we observe power at a spectral peak near the obliquity band ( $43 \mathrm{kyr})$. A time series comparison of $M M V_{\text {China }}$ and obliquity demonstrates that 1) the correspondence between them is not consistent over the past 640 kyrs (Fig. 3c) and 2) $M M V_{\text {China }}$ peaks lead obliquity from 350-640 ka (Fig. 3d). Hence, MMV in Chinese $\delta^{18} \mathrm{O}$ is not modulated by precession and moreover, its relationship with obliquity is complex, as it leads obliquity-driven insolation changes. 
Our analysis shows that the modulating agents of millennial-scale variability in atmospheric methane and in Chinese stalagmite $\delta^{18} \mathrm{O}$ are disparate. Orbitally-paced insolation, via precession, modulates $M M V_{\text {methane }}$ but does not modulate $\mathrm{MMV}_{\text {China }}$. The MMV timeseries are not correlated and also show limited coherence in the primary orbital bands (Figs. 4a and 4b). On the other hand, we find a striking correspondence between $\mathrm{MMV}_{\text {China }}$ and the MMV in Antarctic $\delta \mathrm{D}\left(\mathrm{MMV}_{\text {Antarctica }}-\right.$ see Fig. S4). Significant and in-phase coherence (Fig. $4 \mathrm{c}$ and $4 \mathrm{~d}$ ) between these records indicates a persistent and robust coupling over the past $640 \mathrm{kyrs}$, with trends towards higher magnitude millennialscale variability in both records (particularly pronounced in $\mathrm{MMV}_{\text {Antarctica }}$; Fig. S4d) starting around $\sim 430 \mathrm{ka}$ (Fig. 4c). Ultimately, the MMV in Chinese $\delta^{18} \mathrm{O}$ and Antarctic $\delta \mathrm{D}$ share more commonalities in their modes of temporal variability than that of atmospheric methane - where the latter is modulated by precession.

\section{Discussion}

What does the decoupling of orbital modulation of millennial-scale variability in methane and monsoon intensity imply? Over the past three decades, low-latitude precipitation, via its influence on tropical wetlands, has been proposed to be a major driver of long-term variability in atmospheric methane over glacial cycles [Chappellaz et al., 1990]. Although this interpretation has been challenged [Schmidt et al., 2004; Crowley, 1991], it has also been used to tune ice-core age models to precession cycles [Ruddiman and Raymo, 2003]. Shifts in the intertropical convergence zone (ITCZ) and monsoon rainfall variability have been inferred as causes for orbital and millennial-scale variability in methane [Guo et al., 2011; Brook and Buizert, 2018], with a secondary role for boreal sources [Chappellaz et al., 1997] and a minimal role for "geological" emissions including marine clatharates, seeps, and mud volcanoes [Bock et al., 2017; Petrenko et al., 2017]. Yet the relative contributions of various sources to past methane changes and subsequent significance for future ramifications remains hotly debated [Baumgartner et al., 2012; Kirschke et al., 2013; Schuur et al., 2015; Bock et al., 2017].

Taken at face value, given that precession modulates $\mathrm{MMV}_{\text {methane }}$ and not monsoon intensity (as recorded in Chinese speleothem $\delta^{18} \mathrm{O}$ ), our results point to midlatitude and high-latitude sources as potentially important drivers of the amplitude of methane variability on millennial timescales. Several mechanisms involving boreal sources as major contributors to methane variations have been proposed, including variability in midlatitude wetlands and peatlands from changes in sea-level and hydroclimate [Baumgartner et al., 2012; Bock et al., 2017; Ridgwell et al., 2012], high-latitude permafrost thawing [O'Connor et al., 2010], and emissions from temperature-sensitive thermokarst lakes [Lewkowicz and Way, 2019]. We contend that precession-triggered changes in local summer temperatures and associated hydrological anomalies in extratropical northern latitudes could generate shifts in methane sources through a combination of these mechanisms, and thus explain the modulation of millennial-scale variability in atmospheric methane.

Uncertainty exists in strictly interpreting Chinese speleothem $\delta^{18} \mathrm{O}$ as monsoon rainfall amount. However, even if the speleothem $\delta^{18} \mathrm{O}$ were not a representative metric of the global paleomonsoons [Cheng et al., 2016; Caley et al., 2011] and instead reflected changes in the position of westerlies, or downstream vapor changes in the Indian monsoon domain over millennial timescales [Pausata et al., 2011; Chiang et al., 2015], the remarkable similarity between $\mathrm{MMV}_{\text {China }}$ and $\mathrm{MMV}_{\text {Antarctica }}$ indicates that disparate and distant regional ocean-atmosphere features of the climate system are modulated in the same manner (Fig. 4c-d). The lack of precession in these MMV records suggests that endogenous processes modulate the magnitude of millennial-scale climate variability.

Given these uncertainties in interpreting Chinese speleothem $\delta^{18} \mathrm{O}$, another explanation for our findings is that $\mathrm{MMV}_{\mathrm{China}}$ is modulated purely by high-latitude and inter-

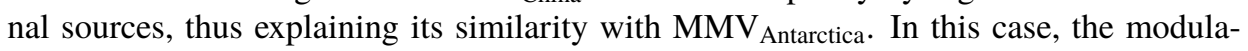


tion of $\mathrm{MMV}_{\text {methane }}$ by precession and lack thereof in the speleothems would imply that $\mathrm{MMV}_{\text {China }}$ is decoupled from tropical rainfall [Clemens et al., 2018; Beck et al., 2018] and that the MMV calculated in records of precipitation from the monsoon and ITCZ domain would contain precessional peaks. Such long, well-resolved and absolutely-dated records of tropical rainfall do not yet exist to refute this hypothesis and moreover, such a scenario would also argue for the decoupling of ITCZ and low-latitude rainfall shifts from the MMV in Chinese speleothem $\delta^{18} \mathrm{O}$. As a preliminary investigation, we found that the MMV in a record of ITCZ changes from the Cariaco Basin [Gibson and Peterson, 2014], off Venezuela (shorter in length compared to the Chinese composite speleothem record), does not contain power in the precessional band as a modulator (Fig. S5). Speleothem $\delta^{18} \mathrm{O}$ from Borneo (Fig. S6), although spanning only $\sim 150 \mathrm{kyrs}$, also does not contain such a peak. These further point to an extratropical origin for the precessional modulation of $\mathrm{MMV}_{\text {methane. }}$

The bipolar seesaw paradigm links millennial-scale climate change between Antarctica and Greenland [Barker et al., 2011; Brook and Buizert, 2018; Siddall et al., 2010]. Barker and colleagues generated a synthetic record of millennial-scale Greenland temperature variability (" $G L_{T \_} s y n$ "), beyond the past glacial cycle derived from Antarctic ice-core $\delta \mathrm{D}$, assuming stationarity in this paradigm [Barker et al., 2011]. Accordingly, $\mathrm{MMV}_{\text {Antarctica }}$ is virtually identical to the MMV in the synthetic series (Fig. S7), which leads to the need for reconciliation: if $\mathrm{MMV}_{\text {methane }}$ is modulated by high-latitude precession via changes in local temperature and hydroclimate, why is this not reflected in $\mathrm{MMV}_{G L_{T_{-} s y n}}$, by extension from $\mathrm{MMV}_{\text {Antarctica }}$ ? One possibility is that the bipolar-seesaw is not stationary [Siddall et al., 2010] over the past 640 kyrs, although more highly resolved records are needed to explore this hypothesis. However, another reconciling explanation is offered by the delayed response of ice-sheets to external forcing. Whereas boreal sources of methane respond rapidly to direct insolation forcing [Lewkowicz and Way, 2019], the waxing and waning of ice-sheets offer more inertia [Abe-Ouchi et al., 2013], thus leading to different variability in the high-latitude isotopic records [Vimeux et al., 2001]. Abrupt changes in far-field, regional climates can be linked through perturbations of the Atlantic meridional overturning circulation [Siddall et al., 2010; Barker et al., 2011], and resultant impacts on hydroclimate - processes often invoked alongside the bipolar seesaw mechanism. Such teleconnections internal to the climate-system can also explain why $\mathrm{MMV}_{\text {China }}$ and $\mathrm{MMV}_{\text {Antarctica }}$ share many common traits. Considering that these records are coherent and in-phase at the obliquity band (Fig. 4d), despite not being in-phase with obliquity-forced changes in insolation (Fig. 3d) nor having power at the precessional bands (Fig. 2h and Fig. S4h), strongly suggests that internal oceanice-atmosphere interactions set the timing and magnitude of their millennial-scale climate variability.

Finally, we note the occurrence of a trend towards higher-amplitude millennial-scale variability in the latter half of the MMV in the Chinese and Antarctic records (Fig. 4c). This trend of increasing MMV in both records is independent of the timestep of the raw datasets (see Fig. S2). The onset of this trend coincides with the Mid-Brunhes Event $(\sim 430 \mathrm{ka})$, when ice-sheets increased in size and the 100-kyr cycle became more prominent [Wang et al., 2003]. Changes in the carbon reservoir as well as the effect of insolation on the Southern Hemisphere have been invoked to explain this event [Yin and Berger, 2010; Wang et al., 2003]. According to our analysis, stronger glacial-interglacial cycles coincide with stronger-magnitude millennial-scale climate variability. As insolation does not trend over the last $400 \mathrm{kyr}$, this observation provides an independent line of evidence that insolation does not modulate $\mathrm{MMV}_{\text {China }}$ nor $\mathrm{MMV}_{\text {Antarctica. }}$ Curiously, we find that there is no trend in the millennial-scale activity of methane before or after this event, which reaffirms our hypothesis that $\mathrm{MMV}_{\text {methane }}$ is modulated by changes in Northern Hemisphere summer insolation linked to precession cycles. 


\section{Conclusions}

We provide a new framework to isolate millennial-scale variability and address its modulation in well-dated late Pleistocene records. We find that precession directly modulates the amplitude and timing of atmospheric methane variations over millennial timescales but not of purported monsoon intensity. At face value, this decoupling implies that fluctuations in midlatitude and high-latitude sources of methane, forced by precession, are important for modulating millennial-scale variability. Conversely, we find a strong link between the MMV in Antarctic $\delta \mathrm{D}$ and Chinese composite speleothem $\delta^{18} \mathrm{O}$, reinforcing a role for Earth-cryosphere-system feedbacks in modulating millennial-scale climate variability in the ice-core and monsoon-sensitive records.

\section{Acknowledgments}

We are grateful to Warren Prell for commenting on a previous version of this manuscript and to Baylor Fox-Kemper who provided input on the statistical analysis. We thank Yoshimi Kubota and Joseph Orchardo for fruitful discussion. KT acknowledges the Brown University Presidential Fellowship and the Department of Geosciences at the University of Arizona. This research was supported by NSF grant AGS-1703123 to KT and JWP. The MMV datasets calculated by the authors are attached as a supplemental spreadsheet and will be archived in publicly available repository upon completion of peer-review.

\section{References}

Abe-Ouchi, A., F. Saito, K. Kawamura, M. E. Raymo, J. Okuno, K. Takahashi, and H. Blatter (2013), Insolation-driven 100,000-year glacial cycles and hysteresis of icesheet volume, Nature, 500(7461), 190-193.

Barker, S., G. Knorr, R. L. Edwards, F. Parrenin, A. E. Putnam, L. C. Skinner, E. Wolff, and M. Ziegler (2011), 800,000 years of abrupt climate variability, Science, 334(6054), 347-351.

Baumgartner, M., A. Schilt, O. Eicher, J. Schmitt, J. Schwander, R. Spahni, H. Fischer, and T. F. Stocker (2012), High-resolution interpolar difference of atmospheric methane around the last glacial maximum, Biogeosciences, 9(10), 3961-3977.

Bazin, L., A. Landais, B. Lemieux-Dudon, H. Toyé Mahamadou Kele, D. Veres, F. Parrenin, P. Martinerie, C. Ritz, E. Capron, V. Lipenkov, M.-F. Loutre, D. Raynaud, B. Vinther, A. Svensson, S. O. Rasmussen, M. Severi, T. Blunier, M. Leuenberger, H. Fischer, V. Masson-Delmotte, J. Chappellaz, and E. Wolff (2013), An optimized multi-proxy, multi-site antarctic ice and gas orbital chronology (aicc2012): 120\&amp;ndash;800 ka, Climate of the Past, 9(4), 1715-1731.

Beck, W. J., W. Zhou, C. Li, Z. Wu, L. White, F. Xian, X. Kong, and A. Zhisheng (2018), A 550,000-year record of east asian monsoon rainfall from10be in loess, Science, 360(6391), 877-881.

Bock, M., J. Schmitt, J. Beck, B. Seth, J. Chappellaz, and H. Fischer (2017), Glacial/interglacial wetland, biomass burning, and geologic methane emissions constrained by dual stable isotopic $\mathrm{ch}_{4}$ ice core records., Proceedings of the National Academy of Sciences, 114(29), E5778-E5786.

Brook, E. J., and C. Buizert (2018), Antarctic and global climate history viewed from ice cores, Nature, 558(7709), 200-208.

Brook, E. J., T. Sowers, and J. Orchardo (1996), Rapid variations in atmospheric methane concentration during the past 110,000 years, Science, 273(5278), 1087-1091.

Caley, T., B. Malaizé, M. Revel, E. Ducassou, K. Wainer, M. Ibrahim, D. Shoeaib, S. Migeon, and V. Marieu (2011), Orbital timing of the indian, east asian and african boreal monsoons and the concept of a 'global monsoon', Quaternary Science Reviews, 30(2526), 3705-3715. 
Carolin, S. A., K. M. Cobb, J. Lynch-Stieglitz, J. W. Moerman, J. W. Partin, S. Lejau, J. Malang, B. Clark, A. A. Tuen, and J. F. Adkins (2016), Northern borneo stalagmite records reveal west pacific hydroclimate across mis 5 and 6, Earth Planet Sci Lett, 439(C), 182-193.

Castañeda, I. S., S. Mulitza, E. Schefuß, R. A. L. dos Santos, J. S. S. Damsté, and S. Schouten (2009), Wet phases in the sahara/sahel region and human migration patterns in north africa, Proceedings of the National Academy of Sciences, 106(48), 20,15920,163 .

Chappellaz, J., J. M. Barnola, D. Raynaud, Y. S. Korotkevich, and C. Lorius (1990), Icecore record of atmospheric methane over the past 160,000 years, Nature, 345(6271), $127-131$.

Chappellaz, J., T. Blunier, S. Kints, A. Dällenbach, J.-M. Barnola, J. Schwander, D. Raynaud, and B. Stauffer (1997), Changes in the atmospheric ch4 gradient between greenland and antarctica during the holocene, Journal of Geophysical Research: Atmospheres, 102(D13), 15,987-15,997.

Cheng, H., R. L. Edwards, A. Sinha, C. Spötl, L. Yi, S. Chen, M. Kelly, G. Kathayat, X. Wang, X. Li, X. Kong, Y. Wang, Y. Ning, and H. Zhang (2016), The asian monsoon over the past 640,000 years and ice age terminations, Nature, 534(7609), 640-646.

Chiang, J. C. H., I. Y. Fung, C.-H. Wu, Y. Cai, J. P. Edman, Y. Liu, J. A. Day, T. Bhattacharya, Y. Mondal, and C. A. Labrousse (2015), Role of seasonal transitions and westerly jets in east asian paleoclimate, Quaternary Science Reviews, 108(C), 111-129.

Clemens, S. C., A. Holbourn, Y. Kubota, K. E. Lee, Z. Liu, G. Chen, A. Nelson, and B. Fox-Kemper (2018), Precession-band variance missing from east asian monsoon runoff, Nature Communications, 9(1), 1-12.

Crowley, T. J. (1991), Ice-age methane variations, Nature, 353(6340), 122.

Extier, T., A. Landais, C. Bréant, F. Prié, L. Bazin, G. Dreyfus, D. M. Roche, and M. Leuenberger (2018), On the use of ?18oatm for ice core dating, Quaternary Science Reviews, 185, 244-257.

Gibson, K. A., and L. C. Peterson (2014), A 0.6 million year record of millennial-scale climate variability in the tropics, Geophysical Research Letters, 41(3), 969-975.

Grinsted, A., J. C. Moore, and S. Jevrejeva (2004), Application of the cross wavelet transform and wavelet coherence to geophysical time series, Nonlinear Processes in Geophysics, 11(5-6), 561-566.

Guo, Z., X. Zhou, and H. Wu (2011), Glacial-interglacial water cycle, global monsoon and atmospheric methane changes, Climate Dynamics, 39(5), 1073-1092.

Hagelberg, T. K., G. Bond, and P. Demenocal (1994), Milankovitch band forcing of submilankovitch climate variability during the pleistocene, Paleoceanography and Paleoclimatology, 9(4), 545-558.

Imbrie, J., E. A. Boyle, S. C. Clemens, W. R. Howard, G. J. Kukla, J. E. Kutzbach, D. G. Martinson, A. McIntyre, A. C. Mix, B. Molfino, J. J. Morley, L. C. Peterson, N. G. Pisias, W. L. Prell, M. E. Raymo, N. J. Shackleton, and J. R. Toggweiler (1992), On the structure and origin of major glaciation cycles 1 . linear responses to milankovitch forcing, Paleoceanography, 7(6), 701-738.

Jouzel, J., V. Masson-Delmotte, O. Cattani, G. Dreyfus, S. Falourd, G. Hoffmann, B. Minster, J. Nouet, J.-M. Barnola, and J. Chappellaz (2007), Orbital and millennial antarctic climate variability over the past 800,000 years, Science, 317(5839), 793-796.

Kirschke, S., P. Bousquet, P. Ciais, M. Saunois, J. G. Canadell, E. J. Dlugokencky, P. Bergamaschi, D. Bergmann, D. R. Blake, L. Bruhwiler, P. Cameron-Smith, S. Castaldi, F. Chevallier, L. Feng, A. Fraser, M. Heimann, E. L. Hodson, S. Houweling, B. Josse, P. J. Fraser, P. B. Krummel, J.-F. Lamarque, R. L. Langenfelds, C. Le Quéré, V. Naik, S. O’Doherty, P. I. Palmer, I. Pison, D. Plummer, B. Poulter, R. G. Prinn, M. Rigby, B. Ringeval, M. Santini, M. Schmidt, D. T. Shindell, I. J. Simpson, R. Spahni, L. P. Steele, S. A. Strode, K. Sudo, S. Szopa, G. R. van der Werf, A. Voulgarakis, M. van Weele, R. F. Weiss, J. E. Williams, and G. Zeng (2013), Three 
decades of global methane sources and sinks, Nature Geoscience, 6(10), 813-823.

Lewkowicz, A., and R. Way (2019), Extremes of summer climate trigger thousands of thermokarst landslides in a high arctic environment., Nat Commun, 10(1), 1329.

Loulergue, L., A. Schilt, R. Spahni, V. Masson-Delmotte, T. Blunier, B. Lemieux, J.-M. Barnola, D. Raynaud, T. F. Stocker, and J. Chappellaz (2008), Orbital and millennialscale features of atmospheric ch4 over the past 800,000 years, Nature, 453(7193), 383386.

Marcott, S. A., T. K. Bauska, C. Buizert, E. J. Steig, J. L. Rosen, K. M. Cuffey, T. J. Fudge, J. P. Severinghaus, J. Ahn, M. L. Kalk, J. R. McConnell, T. Sowers, K. C. Taylor, J. W. C. White, and E. J. Brook (2014), Centennial-scale changes in the global carbon cycle during the last deglaciation, Nature, 514(7524), 616-619.

O’Connor, F. M., O. Boucher, N. Gedney, C. D. Jones, G. A. Folberth, R. Coppell, P. Friedlingstein, W. J. Collins, J. Chappellaz, J. Ridley, and C. E. Johnson (2010), Possible role of wetlands, permafrost, and methane hydrates in the methane cycle under future climate change: A review, Reviews of Geophysics, 48(4).

Pausata, F. S. R., D. S. Battisti, K. H. Nisancioglu, and C. M. Bitz (2011), Chinese stalagmite $\delta^{18}$ o controlled by changes in the indian monsoon during a simulated heinrich event, Nature Geoscience, 4(7), 474-480.

Petrenko, V. V., A. M. Smith, H. Schaefer, K. Riedel, E. Brook, D. Baggenstos, C. Harth, Q. Hua, C. Buizert, A. Schilt, X. Fain, L. Mitchell, T. Bauska, A. Orsi, R. F. Weiss, and J. P. Severinghaus (2017), Minimal geological methane emissions during the younger dryas-preboreal abrupt warming event, Nature, 548(7668), 443-446.

Rhodes, R., E. Brook, J. Chiang, T. Blunier, O. Maselli, J. McConnell, D. Romanini, and J. Severinghaus (2015), Enhanced tropical methane production in response to iceberg discharge in the north atlantic., Science, 348(6238), 1016-1019.

Rial, J. (2000), Understanding nonlinear responses of the climate system to orbital forcing, Quaternary Science Reviews, 19(17-18), 1709-1722.

Ridgwell, A., M. Maslin, and J. O. Kaplan (2012), Flooding of the continental shelves as a contributor to deglacial ch4rise, Journal of Quaternary Science, 27(8), 800-806.

Roder, H. (1931), Amplitude, phase, and frequency modulation, Proceedings of the Institute of Radio Engineers, 19, 2145-2176.

Ruddiman, W. F., and M. E. Raymo (2003), A methane-based time scale for vostok ice, Quaternary Science Reviews, 22(2-4), 141-155.

Schmidt, G. A., D. T. Shindell, and S. Harder (2004), A note on the relationship between ice core methane concentrations and insolation, Geophysical Research Letters, 31(23), 2362-2364.

Schuur, E. A. G., A. D. McGuire, C. Schädel, G. Grosse, J. W. Harden, D. J. Hayes, G. Hugelius, C. D. Koven, P. Kuhry, D. M. Lawrence, S. M. Natali, D. Olefeldt, V. E. Romanovsky, K. Schaefer, M. R. Turetsky, C. C. Treat, and J. E. Vonk (2015), Climate change and the permafrost carbon feedback, Nature, 520(7546), 171-179.

Siddall, M., E. J. Rohling, T. Blunier, and R. Spahni (2010), Patterns of millennial variability over the last $500 \mathrm{ka}$, Climate of the Past, 6(3), 295-303.

Spratt, R. M., and L. E. Lisiecki (2016), A late pleistocene sea level stack, Climate of the Past, 12(4), 1079-1092.

VanderPlas, J. T. (2017), Understanding the lomb-scargle periodogram, arXiv.org, astroph.IM(1), 16.

Vimeux, F., V. Masson, G. Delaygue, J. Jouzel, J. R. Petit, and M. Stievenard (2001), A 420,000 year deuterium excess record from east antarctica: Information on past changes in the origin of precipitation at vostok, Journal of Geophysical Research: Atmospheres, 106(D23), 31,863-31,873.

Wang, P., J. Tian, X. Cheng, C. Liu, and J. Xu (2003), Carbon reservoir changes preceded major ice-sheet expansion at the mid-brunhes event, Geology, 31(3), 239-242.

Yin, Q. Z., and A. Berger (2010), Insolation and co2 contribution to the interglacials before and after the mid-brunhes event, Nature Geoscience, 3(4), 243-246. 

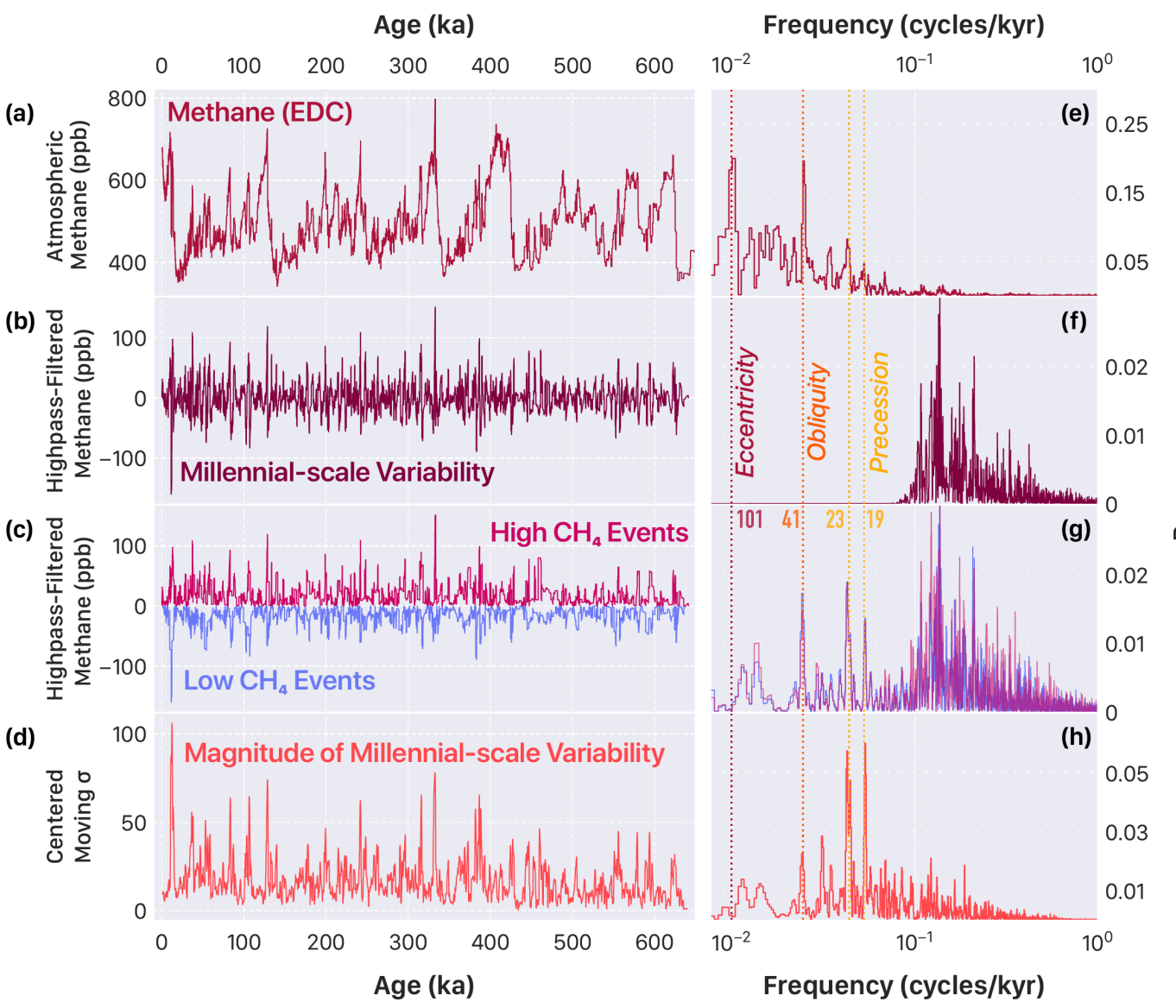

Figure 1. Orbital and millennial-scale atmospheric methane variability over the past 640 kyrs. (a) EPICA Dome $\mathrm{C}$ record of $\mathrm{CH}_{4}$, (b) its millennial-scale variability calculated as the 10-kyr high-pass filtered record of the original time series, (c) high-value and low-value $\mathrm{CH}_{4}$ in the high-pass filtered record, and (d) the magnitude of millennial-scale variability calculated as the centered rolling standard deviation of the highpass filtered record using 2-kyr sliding windows (100-yr step). (e-h) Periodograms of corresponding time series using the Lomb-Scargle methodology. Primary orbital frequencies are marked with dashed lines (19 \& 23 - precession; 41 - obliquity; 101 - eccentricity). Note different scaling for power spectral density. 


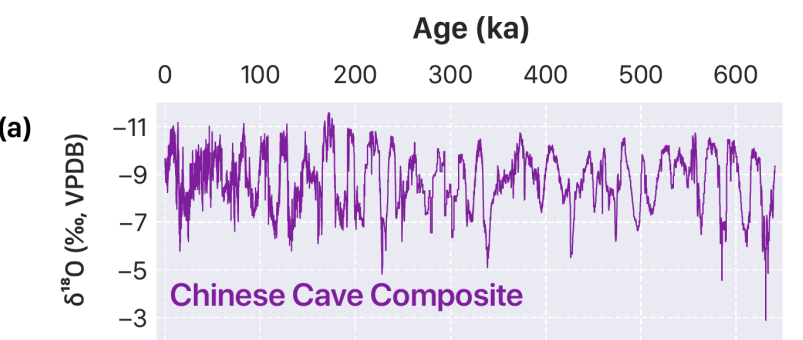

(b)

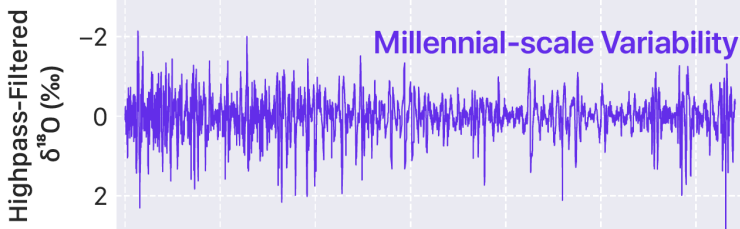

(c)

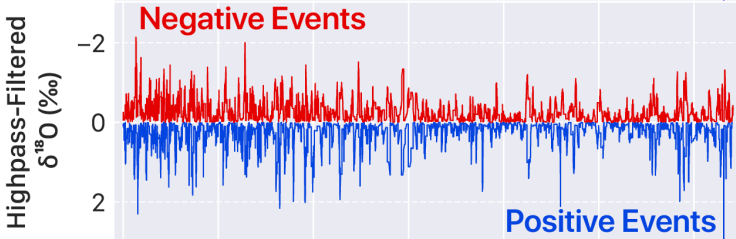

(d)

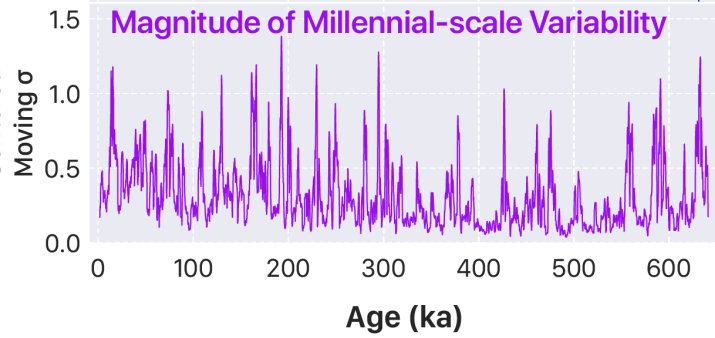

Frequency (cycles/kyr)

$10^{-1}$

$10^{0}$

(e)

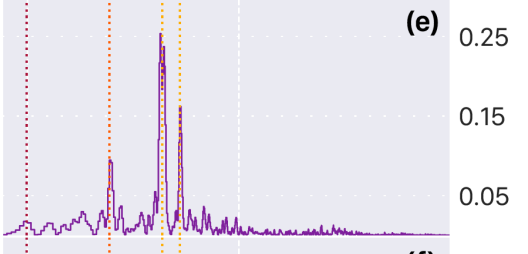

(f)

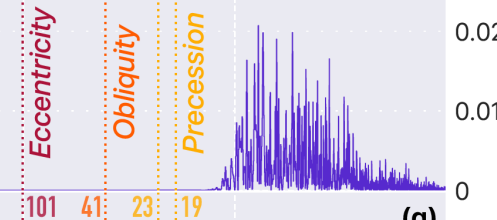

(g)

$\stackrel{\grave{Q}}{\grave{Q}}$

0.02

0.01

(h)

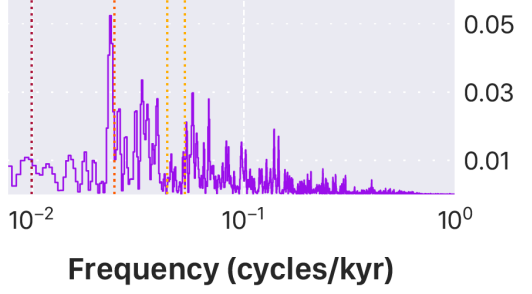

Figure 2. Orbital and millennial-scale variability in the composite Chinese speleothem record over the past 640 kyrs. (a) Chinese speleothem $\delta^{18} \mathrm{O}$ composite, (b) its millennial-scale variability calculated as the 10-kyr high-pass filtered record of the original time series, (c) negative-value and positive-value $\delta^{18} \mathrm{O}$ in the high-pass filtered record, and (d) the magnitude of millennial-scale variability calculated as the centered rolling standard deviation of the high-pass filtered record using 2-kyr sliding windows (100-yr step). (e-h) Periodograms of corresponding time series using the Lomb-Scargle methodology. Primary orbital frequencies are marked with dashed lines ( $19 \& 23$ - precession; 41 - obliquity; 101 - eccentricity). Note different scaling for power spectral density. 
Age (ka)
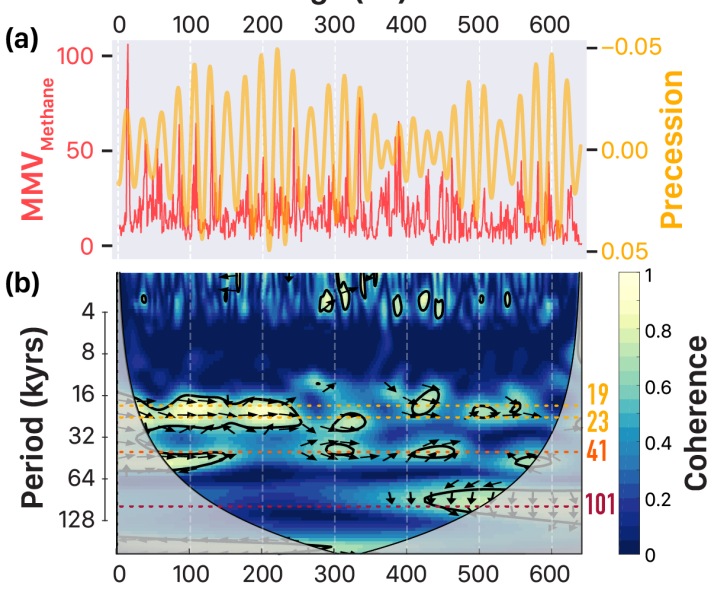

Age (ka)
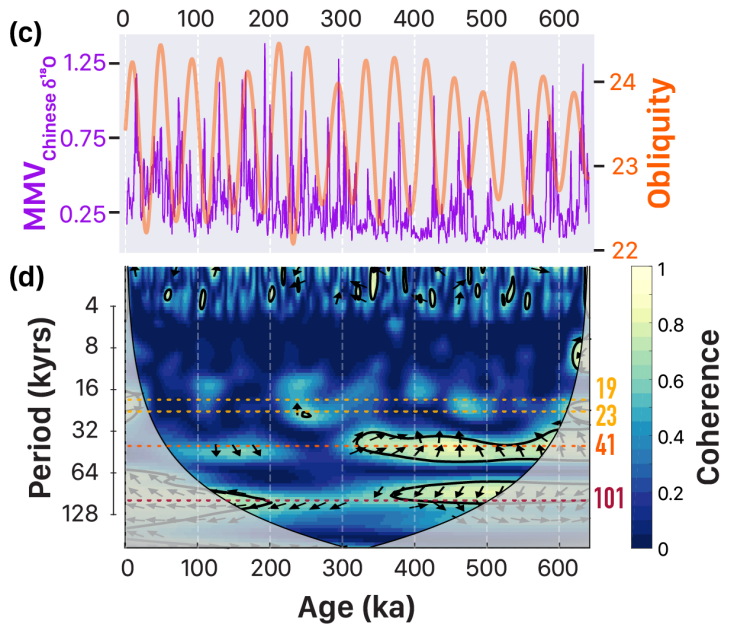

Figure 3. Comparison of orbital forcing and MMV in atmospheric methane and Chinese $\delta^{18} \mathrm{O}$. (a) $\mathrm{MMV}_{\text {methane }}$ (red) compared with precession (yellow), the predominant peak in the $\mathrm{MMV}_{\text {methane }}$ spectra (Fig. 2h) and (b) wavelet coherence between $\mathrm{MMV}_{\text {methane }}$ and normalized eccentricity-tilt-precession (ETP) over the past 640 kyrs. (c) $\mathrm{MMV}_{\text {China }}$ (violet) compared with obliquity (orange), the predominant peak in the $M M V_{\text {China }}$ spectra (Fig. 2h) and (d) wavelet coherence between $M M V_{\text {China }}$ and ETP over the past 640 kyrs. Primary orbital frequencies are marked with dashed lines (19\& 23 - precession; 41 - obliquity; 101 - eccentricity) and lighter colors correspond to stronger coherence. The cone of influence, where edge effects could prevail, has been shaded. Black lines depict significance at the $10 \%$ level (number of Monte Carlo simulations $=1000$ ) and black arrows indicate phase, where those pointing to the right depict zero-phase (upward arrows indicate that the phase of MMV leads ETP). Note that axis for precession is inverted to show higher Northern Hemisphere summer insolation upward and also note that the timeseries comparisons are with (a) precession and (c) obliquity, whereas the wavelet analyses use ETP to test sensitivity with all three aspects of primary orbital forcing. 
Age (ka)

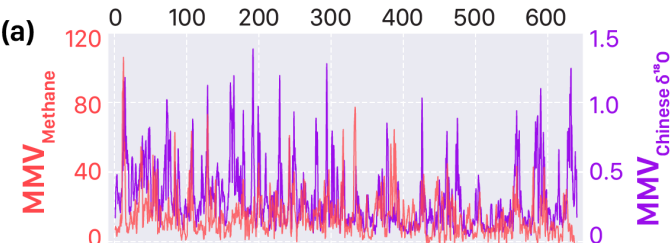

(b)

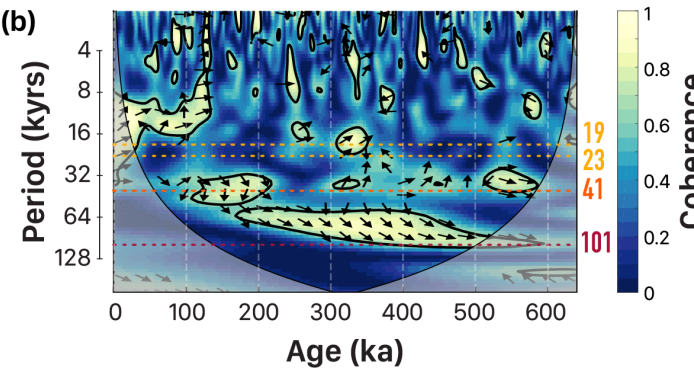

Age (ka)

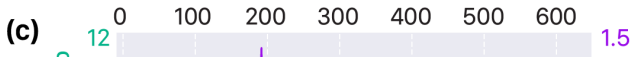

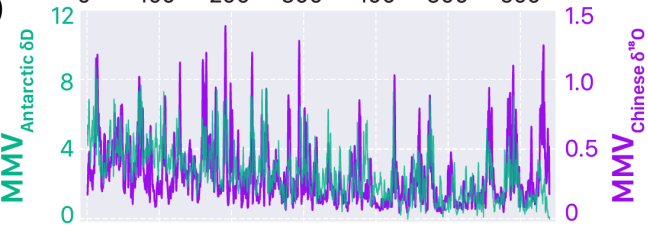

(d)

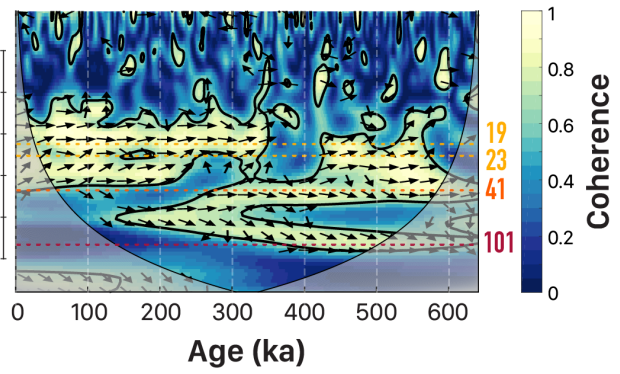

Figure 4. Comparison of MMV in atmospheric methane, Chinese $\delta^{18} \mathrm{O}$, and Antarctic $\delta \mathrm{D}$. (a) $\mathrm{MMV}_{\text {methane }}$ (red) compared with $\mathrm{MMV}_{\text {China }}$ (violet) compared with obliquity (orange) and (b) wavelet coherence between the two records over the past 640 kyrs. (c) $M M V_{\text {China }}$ (violet) compared with $M M V_{\text {Antarctica }}$ (green) and (d) wavelet coherence between the two records over the past 640 kyrs. Primary orbital frequencies are marked with dashed lines (19 \& 23 - precession; 41 - obliquity; 101 - eccentricity) and lighter colors correspond to stronger coherence. The cone of influence, where edge effects could prevail, has been shaded. Black lines depict significance at the $10 \%$ level (number of Monte Carlo simulations $=1000$ ) and black arrows indicate phase, where those pointing to the right depict zero-phase (upward arrows indicate that the phase of MMV leads ETP). 

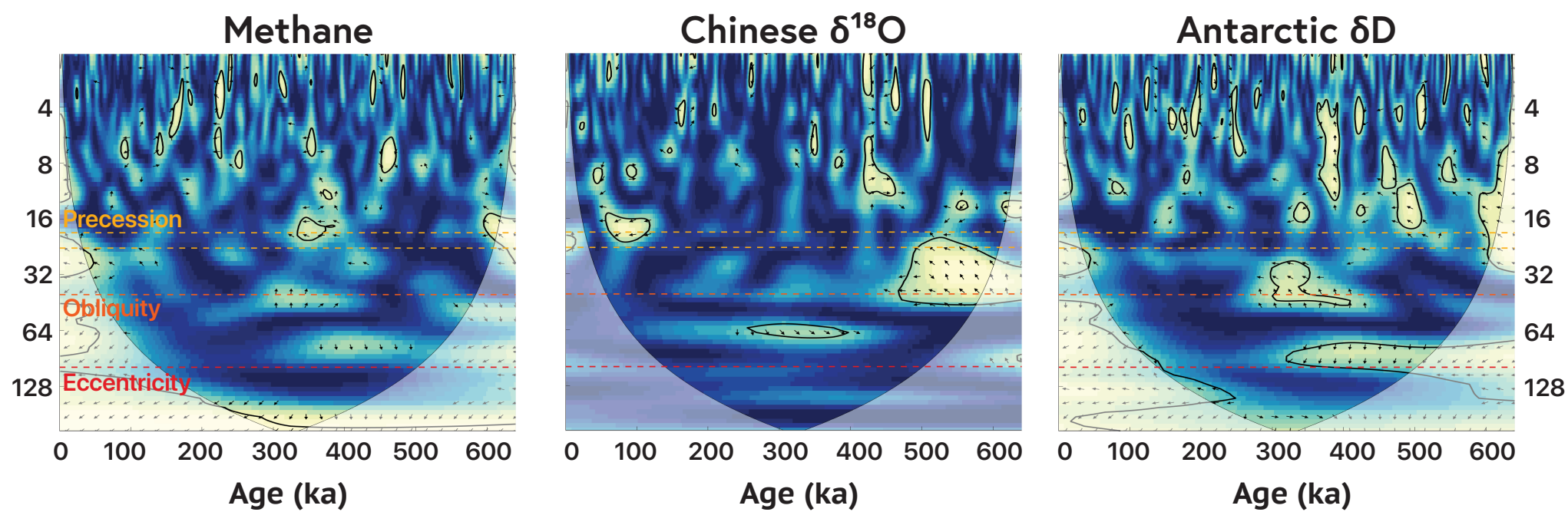

Figure S2. Cross-wavelet analysis of MMV versus the time-step resolution of the raw records themselves. We find no systematic or secular trends in the transferral of variance from one band to another in any of the records, thus indicating that the long-term trends are not sensitive to changes in the resolution of the records. 
Age (ka)

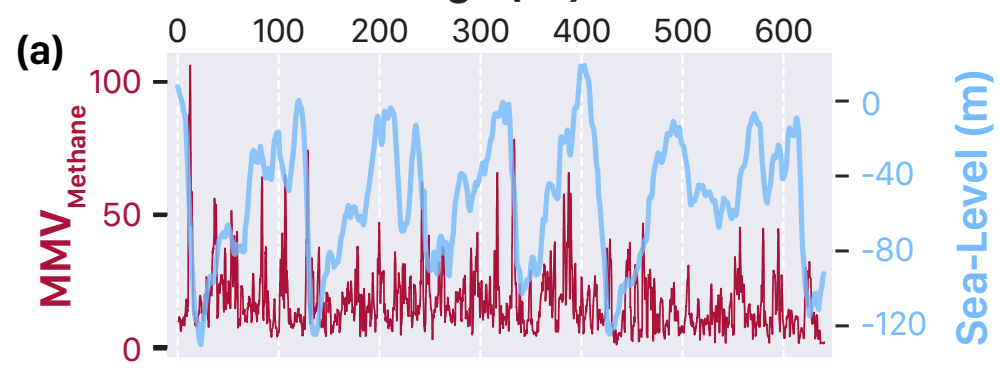

(b)

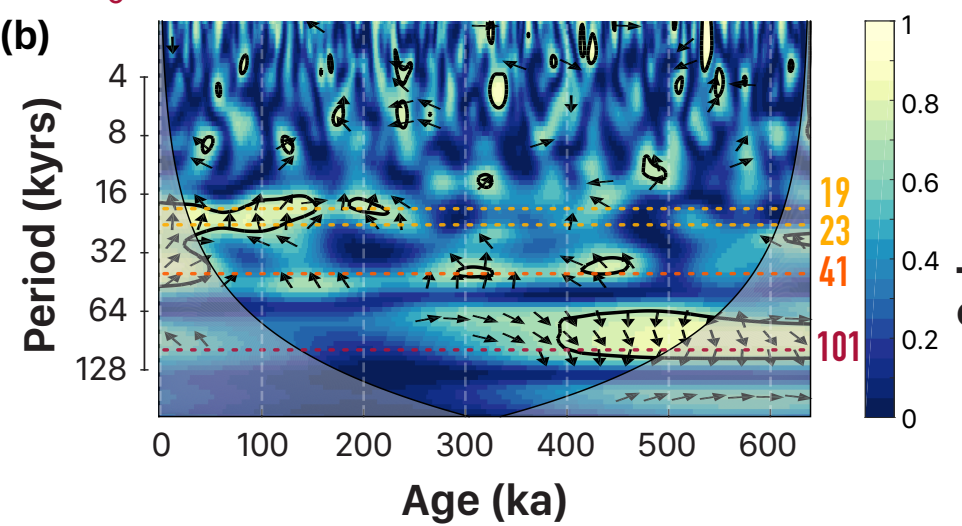

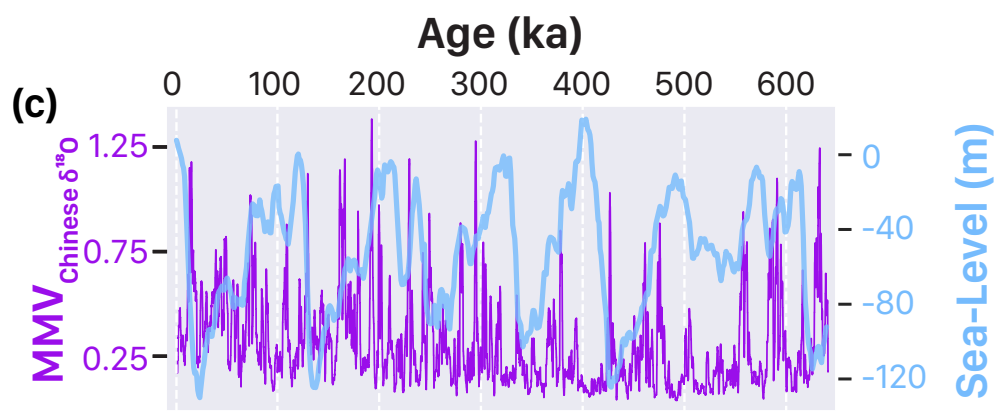

(d)

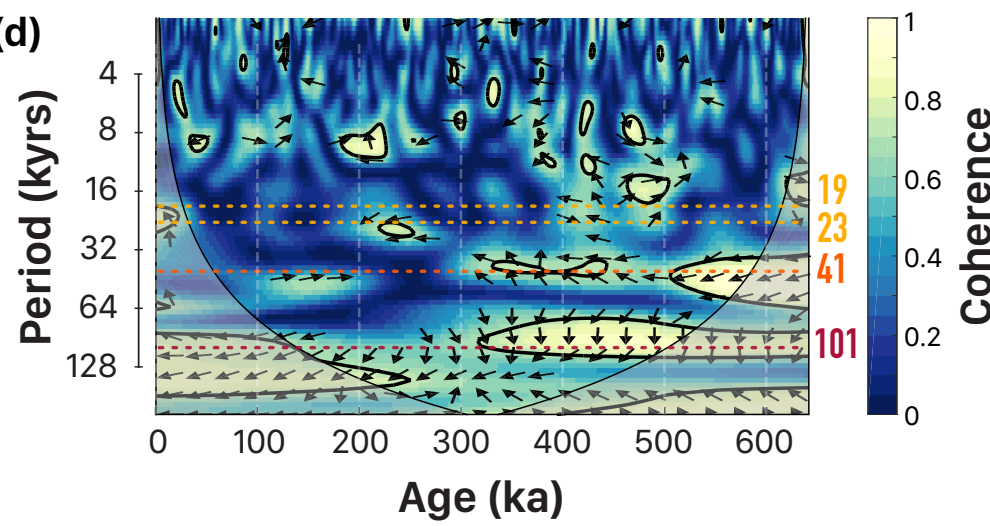

Figure S3. Comparison of sea-level and MMV in atmospheric methane and Chinese stalagmite $\delta^{18} \mathrm{O}$. (a) $\mathrm{MMV}_{\text {methane }}$ (red) compared with sea-level/ice-volume (blue) and (b) wavelet coherence between the two records over the past $640 \mathrm{kyrs}$. (c) $\mathrm{MMV}_{\text {China }}$ (violet) compared with sea-level/ice-volume (blue) and (d) wavelet coherence between the two records over the past $640 \mathrm{kyrs}$. Primary orbital frequencies are marked with dashed lines (19,23 - precession; 41 - obliquity; 101 - eccentricity) and lighter colors correspond to stronger coherence. The cone of influence, where edge effects could prevail, has been shaded. Black lines depict significance at the $5 \%$ level (number of Monte Carlo simulations $=1000$ ) and black arrows indicate phase, where those pointing to the right depict zero-phase (upward arrows indicate that the phase of MMV leads ETP). 
Age (ka)

$\begin{array}{llllllll}0 & 100 & 200 & 300 & 400 & 500 & 600 & 10^{-2}\end{array}$
Frequency (cycles/kyr)

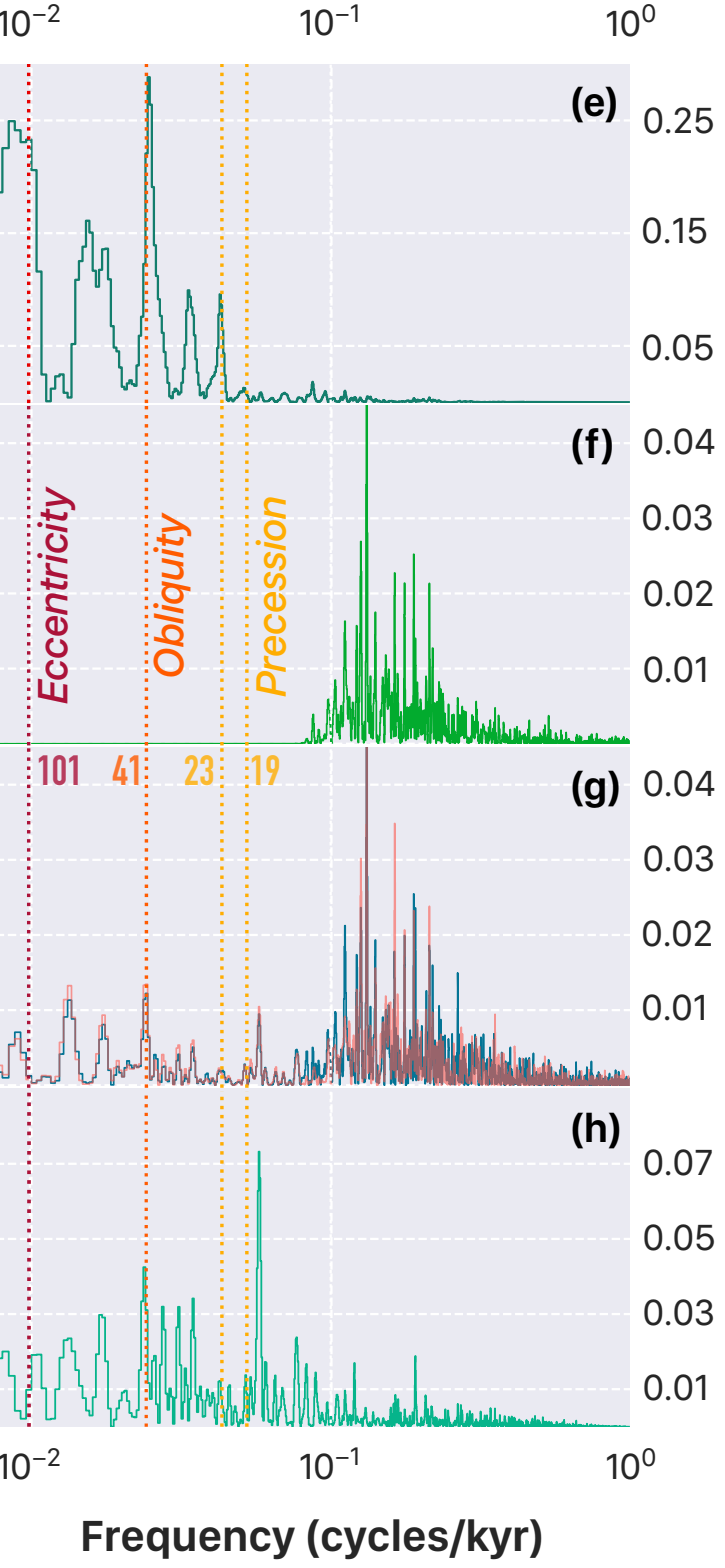

Frequency (cycles/kyr) (a)

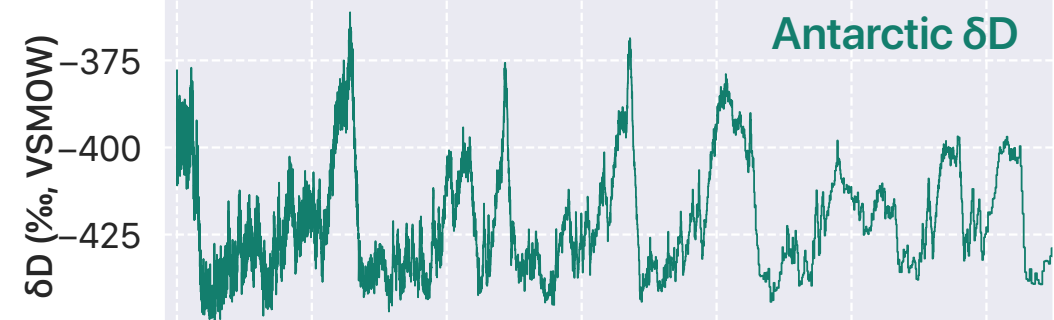

(b)

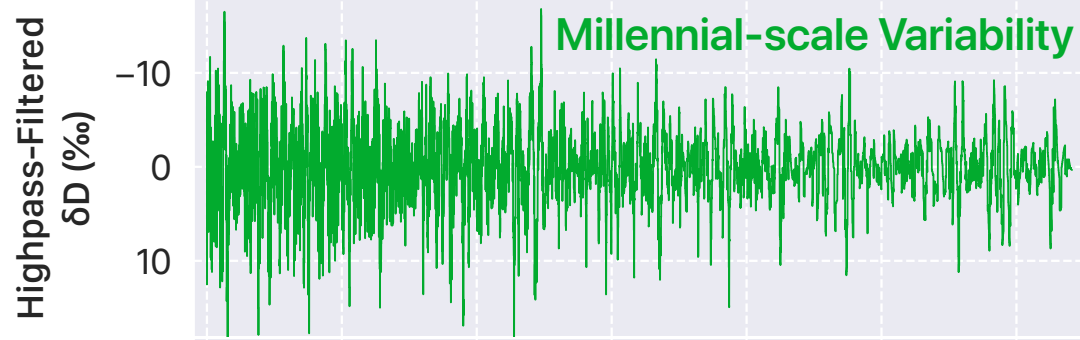

(c)
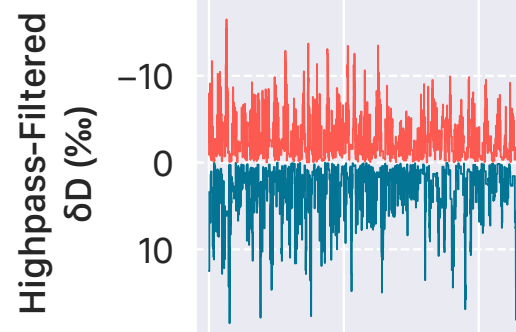

'Warm' Events

(d)

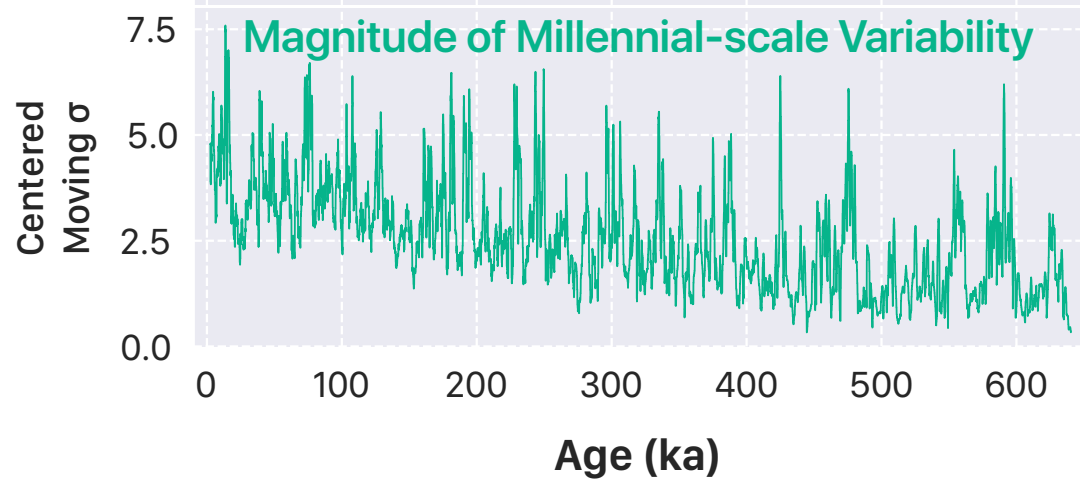

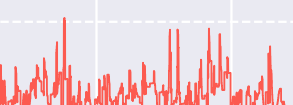
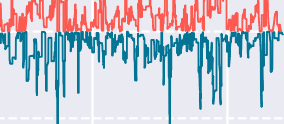

'Cool' Events

Figure S4. Orbital and millennial-scale variability in Antarctic $\delta D$ over the past 640 kyrs. (a) Epica Dome $\mathrm{C}$ record of $\delta \mathrm{D}$, (b) its millennial-scale variability calculated as the 10-kyr high-pass filtered record of the original time series, (c) high-value and low-value $\delta D$ in the high-pass filtered record, and (d) the magnitude of millennial-scale variability calculated as the centered rolling standard deviation of the high-pass filtered record using 2-kyr sliding windows (100-yr step). (e-h) Periodograms of corresponding time series using the Lomb-Scargle methodology. Primary orbital frequencies are marked with dashed lines (19,23 - precession; 41 - obliquity; 101 - eccentricity). Note different scaling for power spectral density. 
Age (ka)

(a)

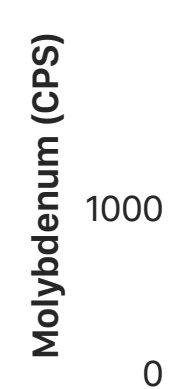

(b)

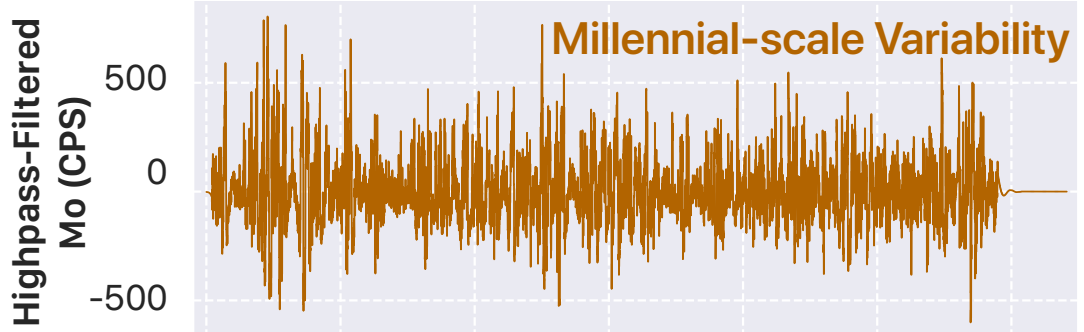

(c)

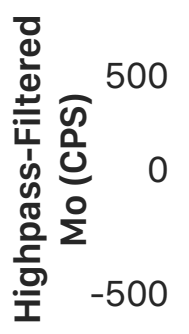

(d)

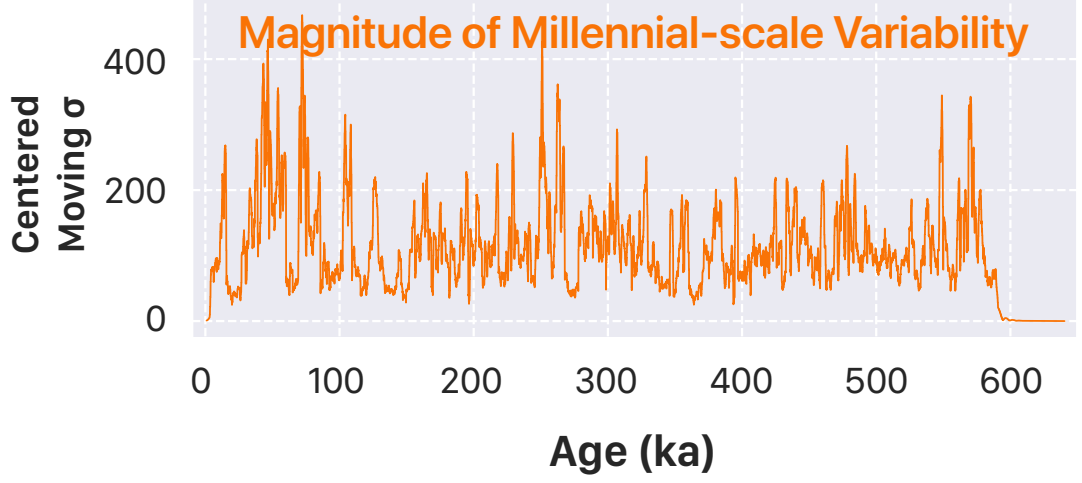

Frequency (cycles/kyr)

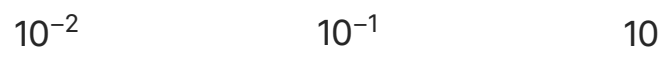

$\int$

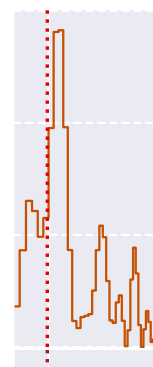

(e) 0.09

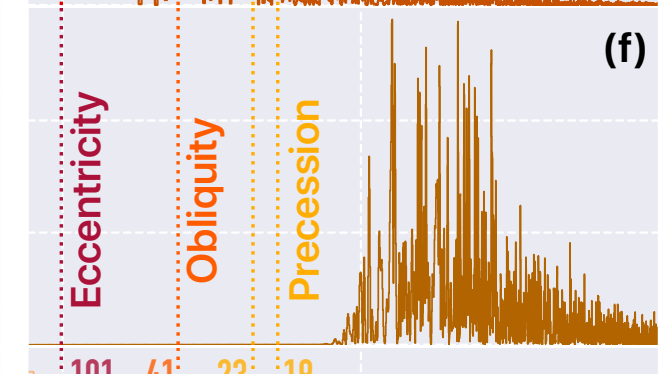

(f)

0.00

0.010

0.005

0.000

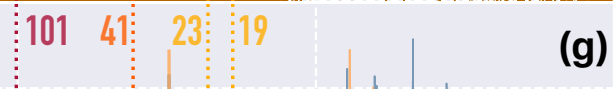

0.015

0.010

0.005

0.000

(h)

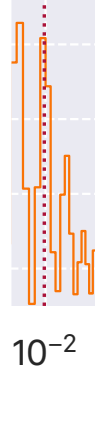

0.07

0.05

0.03

0.01

$10^{-1}$

$10^{0}$

Figure S5. Orbital and millennial-scale variability in molybdenum (Mo) counts in Cariaco Basin over the past 600 kyrs. (a) Composite record of Mo (cps) from MD03-2622 and Site 1002, Cariaco Basin (b) its millennial- scale variability calculated as the 10-kyr high-pass filtered record of the original time series, (c) high-value and low-value Mo in the high-pass filtered record, and (d) the magnitude of millennial-scale variability calculated as the centered rolling standard deviation of the high-pass filtered record using 2-kyr sliding windows (100-yr step). (e-h) Periodograms of corresponding time series using the Lomb-Scargle methodology. Primary orbital frequencies are marked with dashed lines (19,23 - precession; 41 - obliquity; 101 - eccentricity). Note different scaling for power spectral density. 
(a)

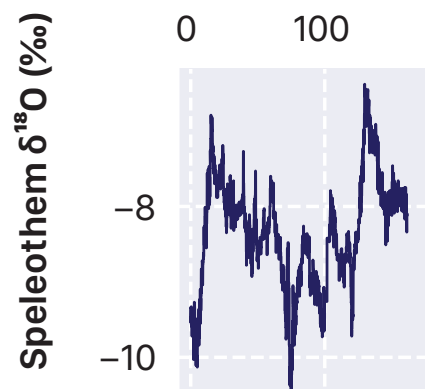

Age (ka)

200

Borneo Speleothem $\delta^{18} \mathrm{O}$

Millennial-scale Variability

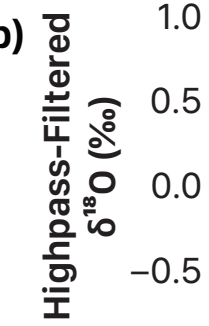

(c)

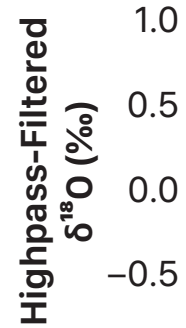

(d)

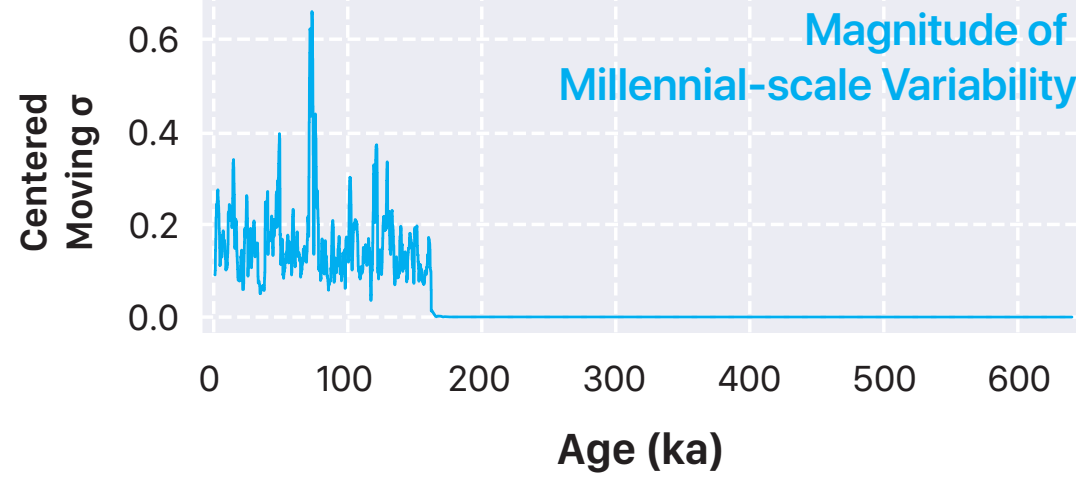

Frequency (cycles/kyr)

$10^{-1}$

$10^{0}$
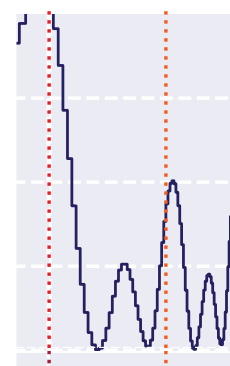

(e)

0.3

0.2

0.1

0.0

(f)

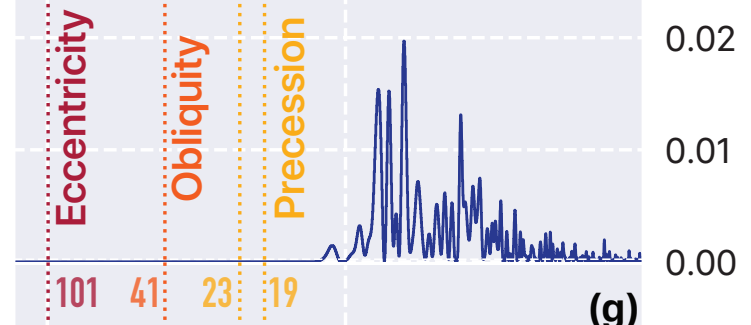

(g)

0.02

0.01

Low-Value Events

Magnitude of

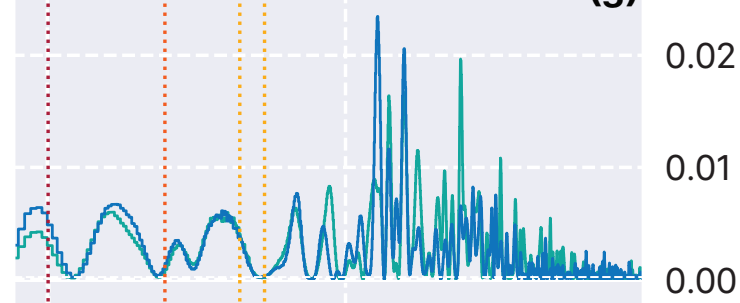

(h)

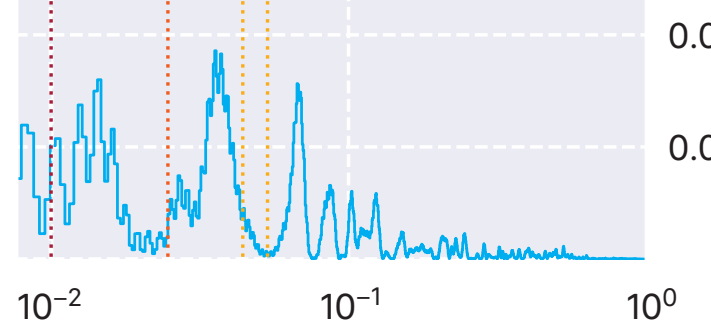

Frequency (cycles/kyr)

Figure S6. Orbital and millennial-scale variability in stalagmite $\delta^{18} \mathrm{O}(\%)$ in Borneo Cave speleothems over the past 150 kyrs. (a) Composite record of Northern Borneo stalagmite $\delta^{18} \mathrm{O}(\% \mathrm{o})$ from Carolin et al. (2015) (b) its millennial- scale variability calculated as the 10-kyr high-pass filtered record of the original time series, (c) high-value and low-value $\delta^{18} \mathrm{O}$ in the high-pass filtered record, and (d) the magnitude of millennial-scale variability calculated as the centered rolling standard deviation of the high-pass filtered record using 2-kyr sliding windows (100-yr step). (e-h) Periodograms of corresponding time series using the Lomb-Scargle methodology. Primary orbital frequencies are marked with dashed lines (19,23 - precession; 41 - obliquity; 101 - eccentricity). Note different scaling for power spectral density and also note that Y-axes for the $\delta^{18} \mathrm{O}$ are lower to the bottom. 


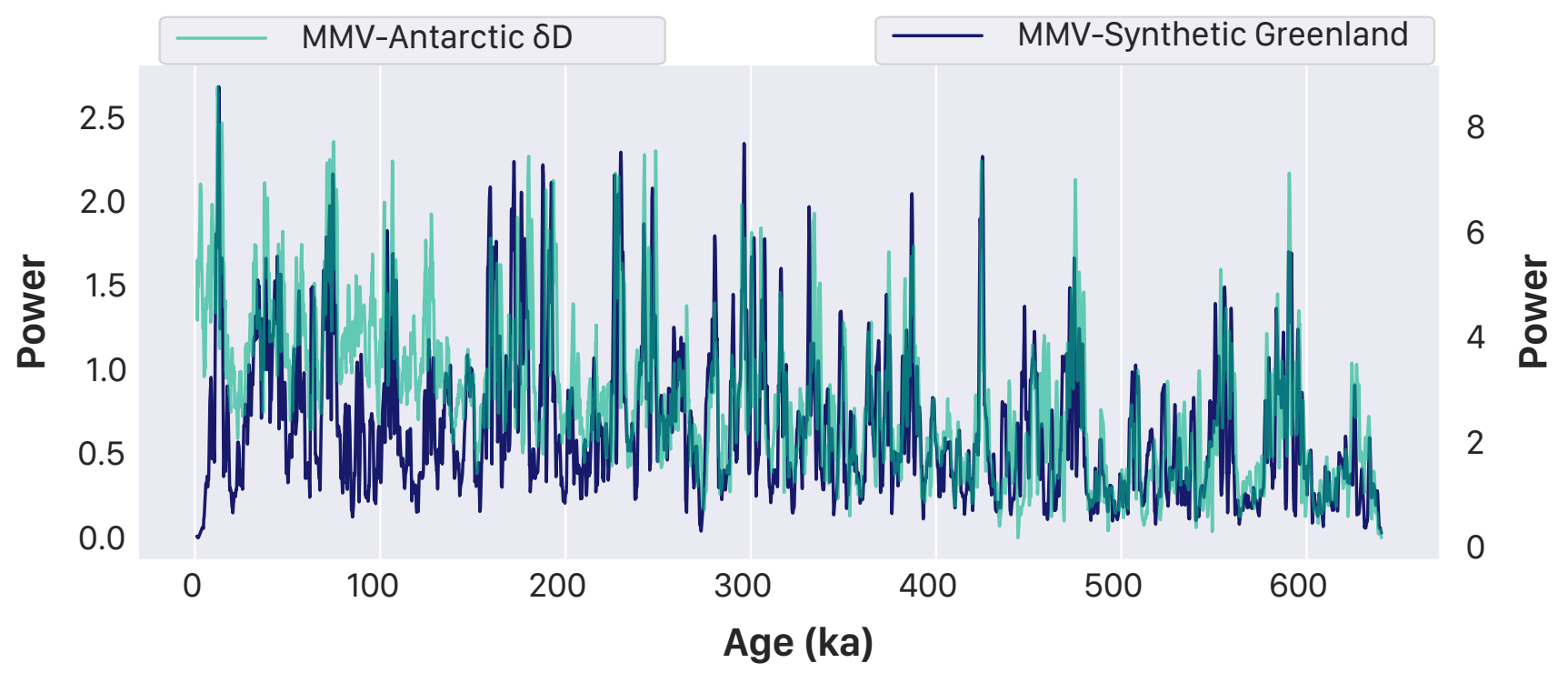

Figure S7. Comparison between the MMV in Antarctic $\delta D$ and the MMV in synthetic Greenland $\delta^{18} \mathrm{O}$. Note that the only discrepencies between the records occur over the past glacial cycle, i.e. over the span of when data exists from the Greenland ice cores. 